\title{
P02.55. Craniosacral therapy for migraine: a feasibility study
}

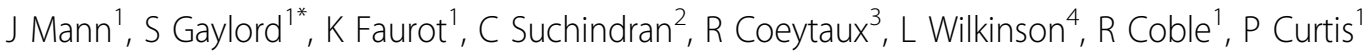 \\ From International Research Congress on Integrative Medicine and Health 2012 \\ Portland, Oregon, USA. 15-18 May 2012
}

\section{Purpose}

The purpose of this study was to evaluate feasibility and obtain preliminary efficacy estimates comparing craniosacral therapy (CST) with an attention-control condition for the adjunctive treatment of migraine.

\section{Methods}

Individuals with moderate to severe migraine were recruited from specialty clinics, family practices, and the university community. After confirmatory clinical evaluation and an 8-week run-in phase, those meeting study criteria (compliant with study procedures, at least 5 migraines per month) were randomized to 8 weekly CST or low-strength static magnet therapy (LSSM) treatments. Study participants were followed for 4 weeks after the conclusion of therapy. Primary outcome measures included headache frequency and headache-specific quality of life (HIT-6). Secondary headache-specific measures include headache-related disability (MIDAS), headache intensity, and abortive medication use.

\section{Results}

At baseline, participants reported a mean 14 headache days per month and severe headache-related quality-of-life impact and disability. Compliance with study procedures was excellent, with 60 of 69 randomized individuals completing 8 weeks of therapy. Individuals in both treatment groups appeared to benefit from the therapy. A significant difference, favoring CST, was noted by treatment group in mean headache hours per day 30 days post treatment ( 1.89 vs. $2.78, \mathrm{p}=0.003)$. HIT-6 scores decreased significantly in both groups, but without a between-group difference at the last treatment visit. MIDAS scores improved in the CST, but not the LSSM group at 4 weeks post treatment. Headache intensity was reduced more in the CST

${ }^{1}$ UNC School of Medicine, Chapel Hill, USA

Full list of author information is available at the end of the article compared with the LSSM group, but the difference was not statistically significant. Abortive medication use decreased substantially in both groups during treatment.

\section{Conclusion}

Our results show that conducting a randomized clinical trial of CST for migraine using a standardized protocol is feasible and that adjunctive CST may reduce headaches in those with severe migraine. Protocol modifications may enhance future investigations of CST for migraine.

\section{Author details}

${ }^{1}$ UNC School of Medicine, Chapel Hill, USA. ${ }^{2}$ UNC Gillings School of Global Public Health, Biostatistics, Chapel Hill, USA. ${ }^{3}$ Department of Community and Family Medicine, Duke University School of Medicine, Durham, USA. ${ }^{4}$ Private practice, Carrboro, USA.

Published: 12 June 2012

doi:10.1186/1472-6882-12-S1-P111

Cite this article as: Mann et al.: P02.55. Craniosacral therapy for migraine: a feasibility study. BMC Complementary and Alternative Medicine 2012 12(Suppl 1):P111.

Submit your next manuscript to BioMed Central and take full advantage of:

- Convenient online submission

- Thorough peer review

- No space constraints or color figure charges

- Immediate publication on acceptance

- Inclusion in PubMed, CAS, Scopus and Google Scholar

- Research which is freely available for redistribution
C Biomed Central

(C) 2012 Mann et al; licensee BioMed Central Ltd. This is an Open Access article distributed under the terms of the Creative Commons Attribution License (http://creativecommons.org/licenses/by/2.0), which permits unrestricted use, distribution, and reproduction in any medium, provided the original work is properly cited. 